\title{
Passive Optical Network Based Intelligent Property System Research
}

\author{
WU Chen, Zhang Hao, Lv Chunshuai, Wang Jiqiang, Yang Le, Tian Dan \\ The Seismological Bureau of Shandong Province, Jinan, 250014, China \\ Email:13953160911@163.com
}

Keywords: The network architecture; Pon technology; Network integration; System construction; Intellectual property

\begin{abstract}
The mitigation of earthquake disasters in Shandong province are briefly introduced composition and function of the intellectual property system, as well as the project background, the demand of construction of the system. Intellectual property system is introduced based on the basic principle of Gpon technology and the construction of the advanced mode. Combination of industry information construction and the development of future business planning, architecture design, from the network technology is introduced, system building, etc., for the construction of the intellectual property system was analyzed, and the passive optical network based intelligent property development direction for the construction of the proposed his own view.
\end{abstract}

\section{Introduction}

In order to better development of earthquake prevention and disaster relief cause of Shandong province, our bureau in Shandong province in 2011 began the construction of the mitigation of earthquake disasters. The park technology system includes: the new research activities building integrated wiring, data center machine room, data communication network, information platform, emergency command center, the intellectual property system, etc. The new intellectual property is a complex system, its operation is based on advanced network construction scheme of GPON technology, not only including security system, access control system, measuring system and the energy consumption of form a complete set of equipment (such as communication and storage system), includes redundant data communications connections, environmental control equipment, monitoring equipment and various safety devices [1]. Now the intellectual property system for this park plays a vital role, is bearing the weight of the daily operation of the entire park, provide us with timely, reliable and efficient service.

\section{Construction Background}

The mitigation of earthquake disasters park technology in the construction of system, seismological bureau of Shandong province in accordance with the "systematic, intelligent, modular, integration" the construction of ideas, fully research the functional requirements and index requirements of the technical system. Function and performance index of the requirements to follow the principle of "practical, advanced, forward-looking", satisfy the operation and management of the existing business system needs, and meet the requirements of the development of future at least 10 to 15 years.

Intellectual property system for the entire park "neural network", is also a park can be the basis for normal operation of the platform. According to specification for design of intellectual property system, the system according to class A intelligent property system design, power equipment host and backstage support according to the redundancy design, air conditioning, etc, to ensure that the communication link uninterrupted. Characteristics of the intellectual property system is based on the optical network, efficient, convenient service for the integration of advanced system, can realize intensive, and scientific management, and compared with other kinds of public network security. The system can provide a for protecting against and mitigating earthquake disasters in Shandong province park intelligent management platform of high reliable, high performance, fully consider the network stability, compatibility and extensibility. Efficiency and security is the core of the 
system requirements, for that the construction of the system response to the specific requirements and comprehensive consideration of the development of network technology. According to the development of information technology and inform the actual situation of the construction of earthquake disasters: construction area is large, the information available, more professional, more requirements and practical application, and the park phase ii, the construction of the three periods of reserve enough space for development. Optical network using Ethernet switches and PON equipment hybrid networking way [2].

\section{Property Management System Present Situation and the Problems We are Facing}

Intellectual property is a sunrise industry, all of the new creatures are all the same to follow the pace of the society, constantly advancing with The Times to obtain long-term development. With the continuous improvement of the social informatization degree, intellectual property is in the process of growth. Property management hierarchy of needs, categories, forms of management mode, need to gradually use information management, improve the work efficiency. To strengthen property management level. Intellectual property management system arises at the historic moment under the background of it is in this system, it is a set of object-oriented system, the distributed structure property[3].

In recent years, the progress of information technology and property management level gradually improve, especially in some cities, property management, intelligence information obtained rapid development. Due to fast development, and thus derived the property management software developers. Software developers are generally more professional computer professionals. As their involvement, the function of property management software, a great change. As the management software is based on the platform, online and other large stand-alone version of management software has become the mainstream in the stage of the product, tend to be more intelligent property management also. With the development of intelligent property, rapid popularization of network technology, computer technology in the future time will be more deeply and widely application popularization in property management, property management will realize seamless and intelligent information management system, intensive management become a reality. At this time of the intellectual property management system will be the application of the wide area network technology, office automation and intelligent systems, financial electronic system, the combination of reflects the development trend of modern property system[4].

\section{The Design Idea and Implementation Approach}

Intelligence property in the whole park is playing an increasingly important role in mitigation of earthquake disasters, the current intellectual property can meet the new demand is put forward under the new environment, improve the service ability and guarantee service of high reliability, high efficiency, reduce our operating costs, achieve the goal of green energy saving [5]. In order to adapt to the trend of the development of the property management system and the park construction and the needs of the development of the future to run all of the intellectual property system is based on the technology of GPON optical network platform.

The Introduction of PON Technology. Called the PON English Passive 0 optical network, translated into Chinese for Passive optical networks, is refers to the optical distribution network does not contain any electronic devices and electronic power, optical distribution network (dn) 0 all consists of optical divider and other Passive components. A passive optical network including center office end device optical line terminal (0 lt) and the user terminal equipment $(0 \mathrm{nu})$ optical network unit. $0 \mathrm{dn}$ used to connect to $0 \mathrm{lt}$ and $\mathrm{ONU}$, including passive optical splitter, optical fiber and coupler. Hold the Ethernet, voice, video, high-definition can networks, such as business, from OLT $\sim$ I | ONU is using a fiber-optic access, 0 nu can use a cable or Ethernet cable to the user equipment. PON technology belong to point to multipoint fiber according to the technology, is the mainstream of the world's broadband access technology, compared with the point-to-point active optical network technology, the cost of PON technology is not high, the maintenance is relatively simple, 
its transmission bandwidth is wide. With the number of Internet more and more, is becoming more and more high to network bandwidth requirement, PON technology to meet the rapid growth of the bandwidth requirements[1].

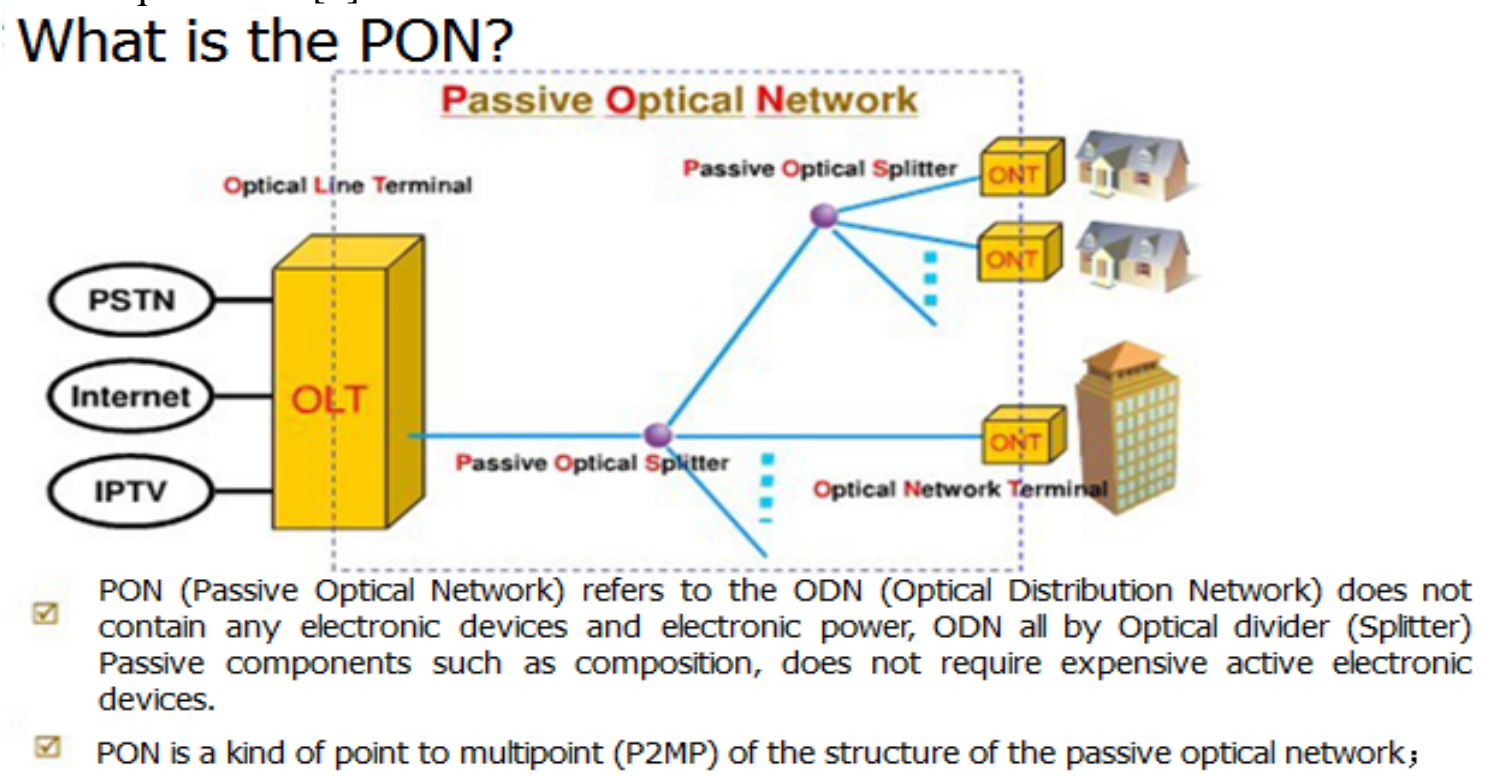

Fig. 1 Gpong technical brief sketch

Network Platform to Build. Traditional tree structure is based on the binary tree structure, adopts vertical scaling method, by adding higher layer and the expansion of higher performance of switch devices. But the topology is difficult to overcome the inherent defects of traditional tree structure: the flow in the core collection root node, the pass is hot, the core node easily become the bottleneck of network performance; Network has such problems as serious overload [5]. In order to overcome the traditional network mode inconvenience we network using Ethernet switch when mixed with PON equipment networking model. Core layer adopts double machine core switching mechanism configuration; In the access layer of floor focused on access mode of double linked to the core switch, other floor adopts the PON equipment networking, OLT equipment placed in the core room, in each floor of each floor beam splitter based on the demand configuration, information on each node according to the specific needs configuration ONU equipment[6]. Network integration is development trend of network building, through fusion can achieve lower costs, reduce the management complexity, improve security advantages [7]. The intellectual property system construction goal is: to realize office automation, information sharing, and scientific management, and compared with other kinds of common network security. Traditional property management system model has not adapted to the development of The Times and realistic demand, the advanced intelligent property system to be able to provide mitigation of earthquake disasters in Shandong province park property management platform of a high reliable, high performance, fully consider the network stability, compatibility and extensibility of the system.

Building Intelligent Property System. This system includes security system: the main courtyard and the building environment for video surveillance and perimeter, Access control system: mainly on the site's main entrance and underground car park entrance sets smart gate vehicle management, energy consumption Metering system: and expansion on the basis of energy metering system in the engine room, statistical analysis of electricity consumption on each floor.

Security System. The Construction Requirements. Realize to park in the monitoring area of real-time video monitoring, image storage, historical images query; Monitoring network and content breadth of coverage, monitoring network should be fully covered in key areas, monitoring content video monitoring system should be adapted to the needs of the business. 


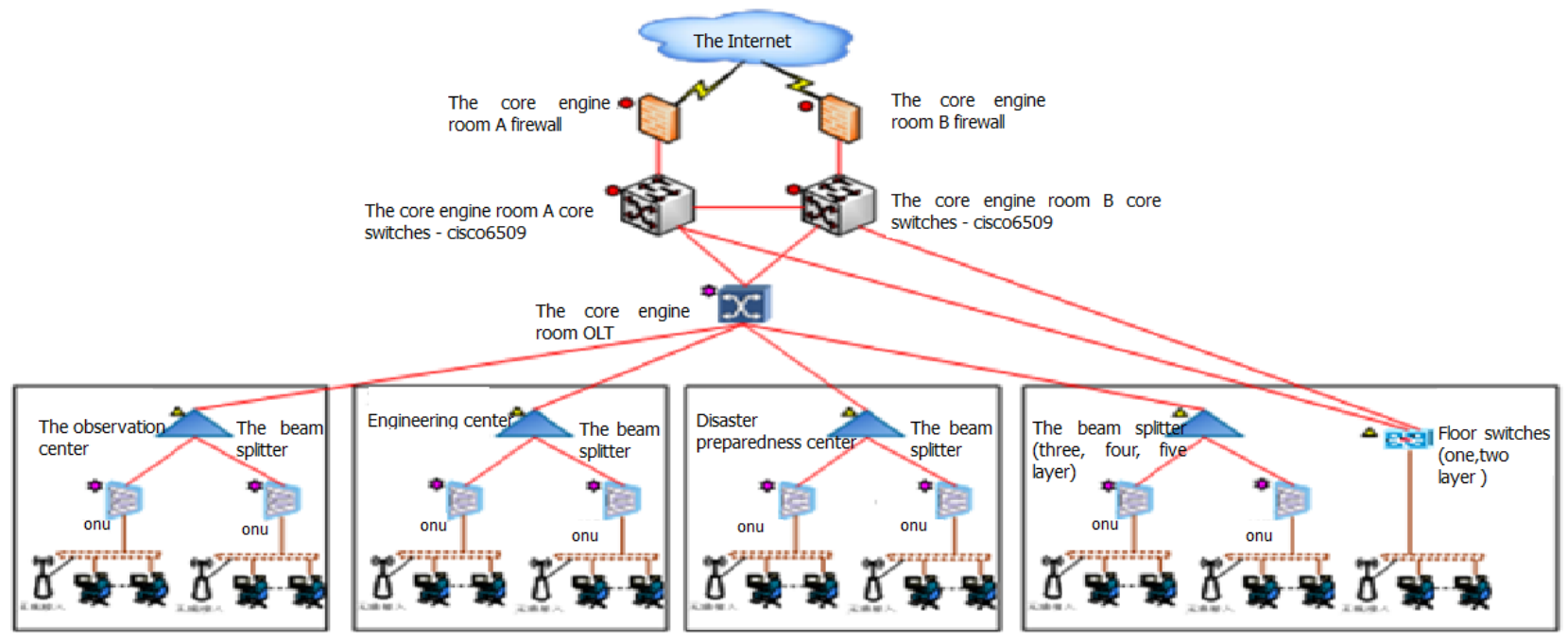

Fig.2 Internet network topology diagram

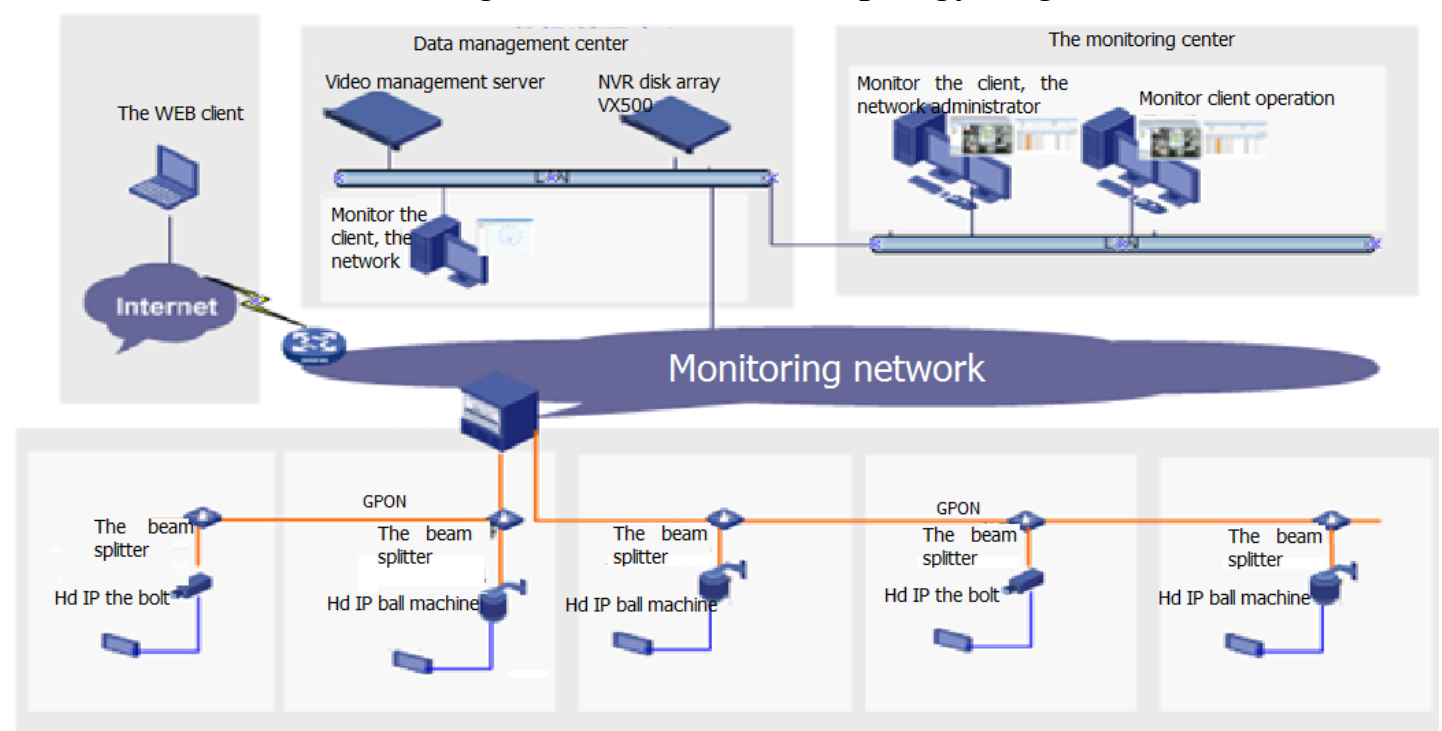

Fig. 3 Schematic diagram of security system

Equipment Layout. Storage devices: according to the design requirements of the original design stored for 30 days, in the center of the third floor room set up three sets of yu VX500 storage devices, storage space for $42 \mathrm{t}$. Display equipment: in monitoring control room set up four client computer and four sets of 42 inch LCD TV, TV wall functions in the most practical and economical way. At the same time, through the HDMI transmission, the sound amplification functions. Front-end equipment: according to the design and change the file, the system set up 64 cameras (including: southern district 9 sets of comprehensive lab building 19, networks center 9 units, 15 units observation, three emergency center, north outside 9 units). Infrared correlation: according to the design requirements, this system has access to the infrared correlation equipment 12 (9 to the north, south to 3, and 6 to standby).

Minimum Energy-Control Systems. The Construction Requirements. In response to a call to conserve energy, total into the box on each floor in the park, the total power consumption of monitoring, remote meter reading. This system platform for the east electronic Indu View power equipment in the center of the three layer data environment monitoring center has been set up, this expansion was carried out on the platform, the debugging. 


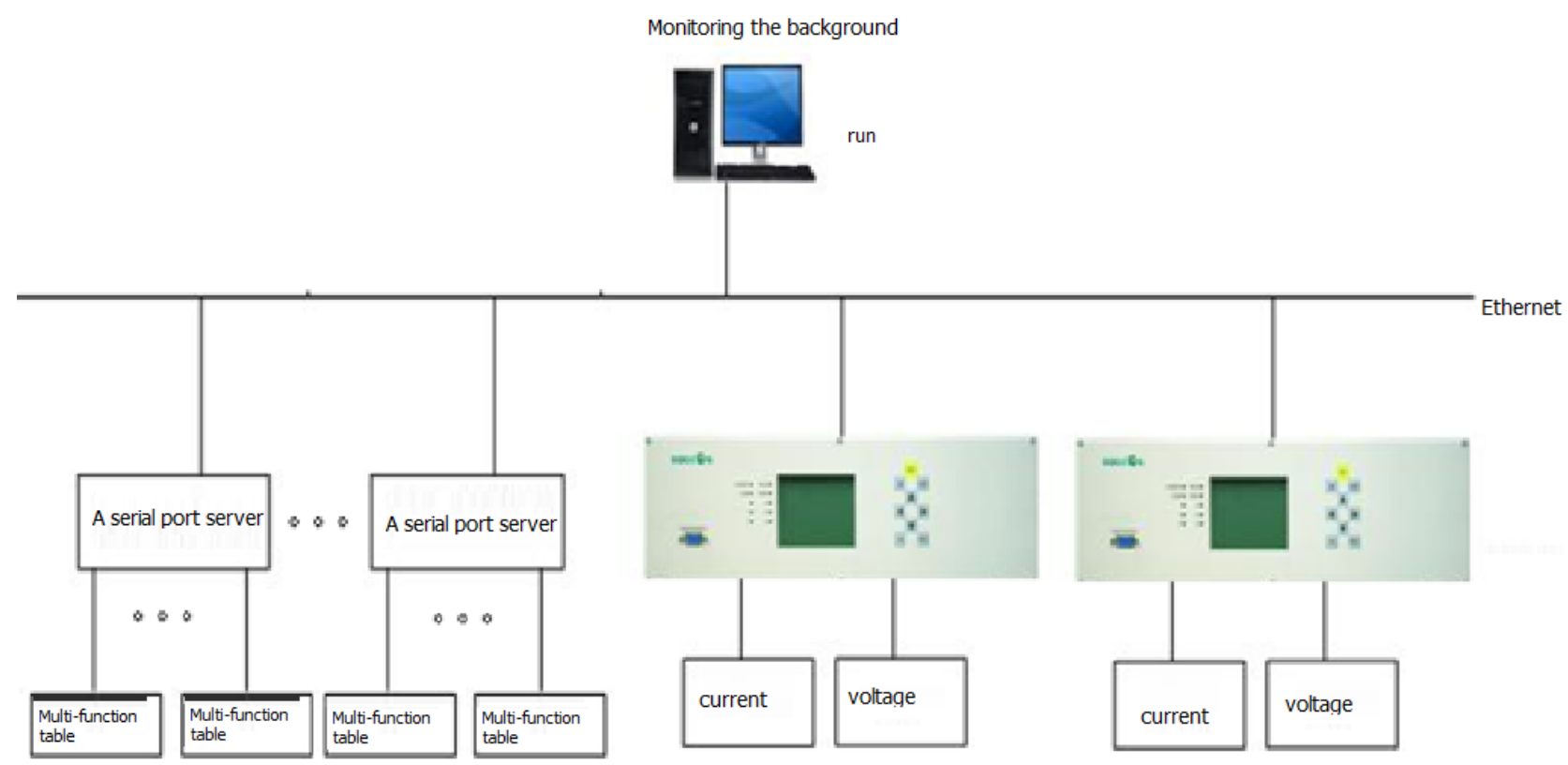

Fig. 4 Schematic diagram of energy consumption measurement

Equipment Layout. Centralized power metering device: transformer room in the center of the observation and comprehensive lab building at level 5, respectively set up a centralized power metering device, the center and the comprehensive lab building electricity metering. And through the network system to transmit data to the data center. Intelligent monitoring instrument: in southern observatory, network center and disaster preparedness center each layer set a intelligent monitoring instrument, through a serial port server to transmit data to the data center. For the floor distribution of electricity metering. Ac transformer, transformer in the corresponding power distribution cabinet installation, implementation of three phase current, voltage, power monitoring, etc.

Gateway Control System. The Construction Requirements. Entrance control system for the main entrance to the park and the underground parking garage management design, the main inlet and outlet, respectively, set brake, underground garage entrances to set a brake, meet in use at the same time. Inward and outward set card reader for the use of the worker and the official access over a long distance.

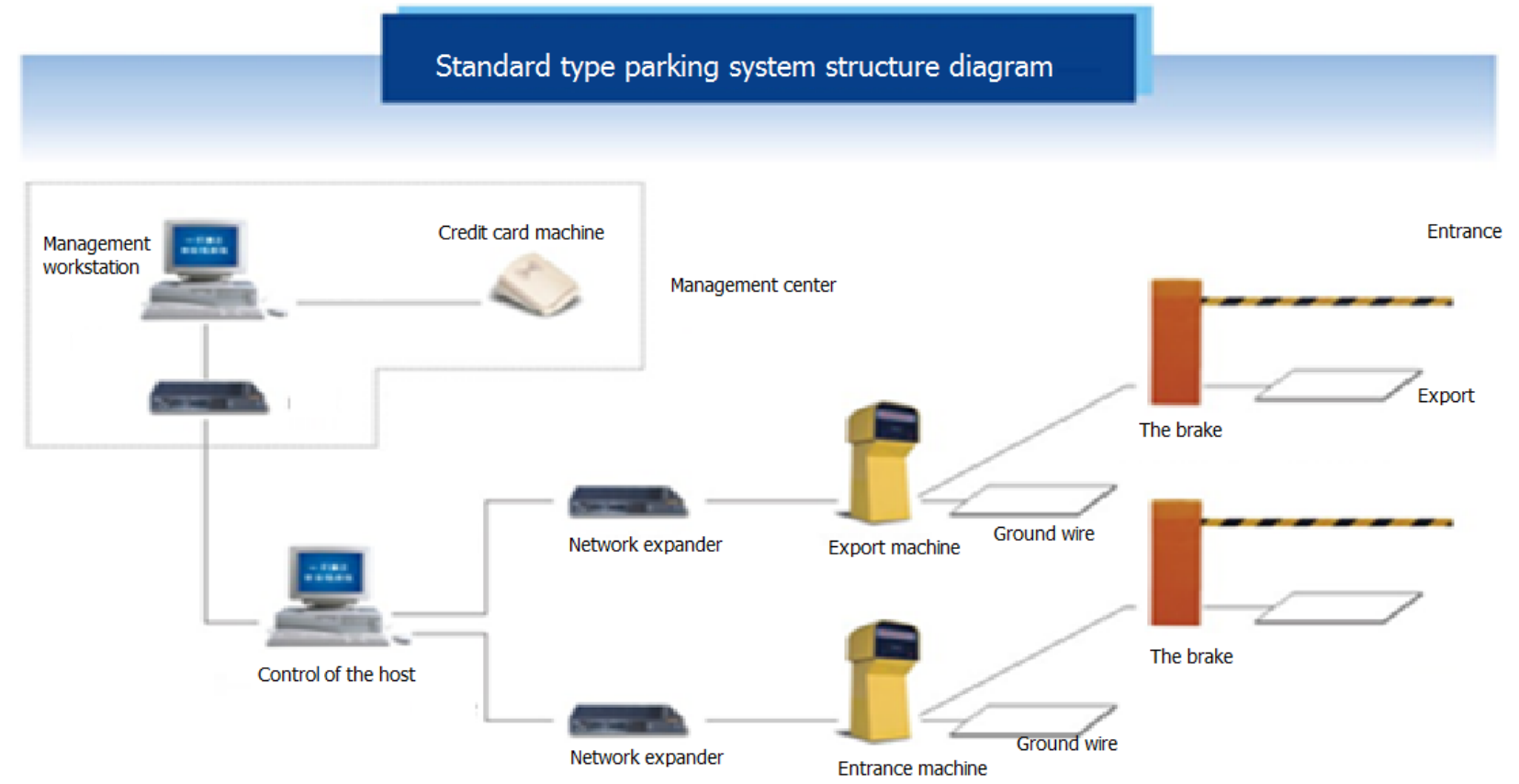

Fig 5 Schematic diagram of the control system of the parking lot.

Equipment Layout. Simon luxury gate: the gate two sets, a set of standby. City: Simon, two sets of the door, two sets of backup. Two sets of card reader: Simon the doorway, two sets of backup. 
Remote controller: Simon, two sets of the door, two sets of backup. Network expander: Simon, two sets of the door, two sets of backup. Credit card machine: Simon is designed.

\section{Conclusion}

With the development of information technology, I use the existing mature technology, technology of earthquake disasters in Shandong province park construction support system of basic information platform. According to the concept of "intellectual property" advanced construction, on the basis of the original hardware server and storage resources, new hardware server and storage resources, and use the advanced optical network has been built, establish intelligent property background data processing and storage and unified supporting platform, provides the reliable infrastructure services, comply with the technology trend of development of the industry in the future. To sum up, the advanced intelligent property system based on optical network has been in protecting against and mitigating earthquake disasters in Shandong province park give full play to the advantage of its role. we also hope that efficient operations of the system can better serve our cause of protecting against and mitigating earthquake disasters.

\section{References}

[1] Wu Chen, Wang Fang-jian, etc., 2012. The virtualization technology in the application of seismic information network business [J]. Earthquake geomagnetic observation and study, 32 (3/4) : 250-255.

[2] Wu Chen, Fang Xiao-liang, etc., 2013. The GPON optical fiber technology in the application of seismic information network in shandong [J]. Journal of earthquake defense technology,. 8 (1) : 104-111.

[3] Yong-hong huang, 2013. The design of the intelligent property management system and research [J]. Journal of henan science and technology, 36 (10) : 80.

[4] Li gang, Sun Jing-yan, etc., 2012. The MPLS VPN in tianjin earthquake monitoring system of high speed LAN applications [J]. Journal of earthquake defense technology, 7 (1) : 92-99.

[5] Yu Kan, 2011. The era of cloud computing data center construction and development [J]. Journal of information and communication, 166 (6) : 100-102.

[6] Qu Zhi-Jian, 2012. The light field network coding node model based on logic operation [J]. Journal of electronics, 40 (7) : 1304-1308. 